\title{
HISTÓRIA PÚBLICA E IMPRENSA: UM OLHAR SOBRE A HISTÓRIA DO ACRE A PARTIR DAS NARRATIVAS EM JORNAIS ACERCA DE SUA ANEXAÇÃO
}

\author{
Nedy Bianca Medeiros de Albuquerque ${ }^{1}$
}

\begin{abstract}
Resumo
A partir da "Questão do Acre" retratada nos periódicos da capital federal, de Belém e Manaus publicados entre 1890 a 1909, se traz reflexões acerca do contributo da escrita da trajetória acriana por meio da História Pública. As pesquisas foram feitas nos acervos da Hemeroteca da Fundação Biblioteca Nacional do Brasil. O referencial é constituído por Albuquerque ${ }^{2}$; Almeida, Rovai ${ }^{3}$; Barbosa ${ }^{4}$; Barros $^{5}$; Cunha $^{6}$; Galvão ${ }^{7}$; Luca $^{8}$; Tocantins ${ }^{9}$ e Silva ${ }^{10}$. Em termos estruturais, no introito do artigo há relato do que foi a "Questão do Acre", depois apontamentos sobre o marco temporal e aporte teórico-metodológico, seguido de diálogo a respeito de como a História Pública pode fazer repensar a escrita da História do Acre, complementado com ponderações quanto ao corpus documental e resultados da pesquisa, que fortalecem o desenvolvimento de um historiografia acriana desconstruindo narrativas laudatórias de mitos.
\end{abstract}

Palavras-chave: Acre; Jornais; História Pública.

\begin{abstract}
From the "Question of Acre" portrayed in the journals of the federal capital, Belem and Manaus published between 1890 and 1909, reflections are brought about the contribution of writing the acriana trajectory through Public History. The research was made in the Brazilian National Library Foundation (Hemeroteca). The reference consists of Albuquerque; Almeida, Rovai; Barbosa; Barros; Cunha; Galvão; Luca; Tocantins and Silva. In structural terms, in the introitus of the article there is a report of what was the "Acre Question", then notes about the time frame and theoretical-methodological contribution, followed by dialogue about how Public History can rethink the writing of the History of Acre, complemented with weightings regarding the documentary corpus and research results, which reinforce the development of an acriana historiography deconstructing laudatory narratives of myths.
\end{abstract}

Keywords: Acre; Public History; newspaper.

\footnotetext{
1 Professora lotada no Centro de Filosofia e Ciências Humanas da Universidade Federal do Acre. Atualmente, exerce o cargo de sub-coordenadora do Curso de Licenciatura em História. É pesquisadora do Núcleo de Estudos Afro-Brasileiros e Indígenas (NEABI/UFAC). E-mail: biancaalbuquerquem@gmail.com

2 ALBUQUERQUE, Nedy Bianca Medeiros de. A cavalo dado não se olham os dentes: o Bolivian Syndicate e a Questão do Acre na imprensa (1890-1909). Tese de Doutoramento em História Social pela FFLCH da USP: São Paulo, 2015.

3 ALMEIDA, Juliele Rabêlo de; OLIVEIRA ROVAI, Marta Gouveia de (Org.). Introdução à História Pública. São Paulo: Letra e Voz, 2011.

${ }^{4}$ BARBOSA, Marialva. História Cultural da Imprensa: Brasil, 1800-1900. Rio de Janeiro: Mauad X, 2010. ${ }^{5}$ BARROS, José D’Assunção. A fonte histórica e seu lugar de produção. In: Caderno de Pesquisa do CDHIS/UFU. v.25, n.2, jul./dez. 2012. p. 407-429. Disponível em: <http://www.seer.ufu.br/index.php/cdhis/article/view/15209/11834> Acesso em: 04 mar. 2020.

${ }^{6}$ CUNHA, Euclides. À margem da História. São Paulo: Martins Fontes, 1999

${ }^{7}$ GALVÃO, Walnice N. No calor da hora: a guerra de canudos nos jornais. 3.ed. São Paulo: Ática, 1994.

${ }^{8}$ LUCA, Tania Regina de. Fontes Impressas: História dos, nos e por meio dos periódicos. In: PINSKY, Carla Bassanezi (org.). Fontes históricas. São Paulo: Contexto, 2005. 116 p.

${ }^{9}$ TOCANTINS, Leandro. Formação Histórica do Acre. 4. ed. Brasília: Senado Federal, 2001. 2 v. 548p.

${ }^{10}$ SILVA, Francisco Bento da. Insolitudes acres, hibridas e fronteiriças: as disputas pelas identidades. Revista Jamaxi, v. 1, p. 49-67, 2017.
} 


\section{Introdução}

Em termos territoriais a configuração atual do Brasil teve o início de sua construção com a partilha do Novo Mundo entre portugueses e espanhóis pela Bula Intercoetera de 1493 e Tratado de Tordesilhas de 1494. A partir das ocupações dos ibéricos na América do Sul outros tantos acordos lindeiros foram feitos, de tal ordem que o Brasil nos primeiros anos do século XIX tivesse as suas fronteiras configuradas a semelhança de seus contornos atuais ${ }^{11}$ excetuando-se partes do Acre, Amapá e Rio Grande do Sul.

Contudo, somente na Primeira República se realizaram as negociações definitivas entre o governo brasileiro e os vizinhos fixando os limites. E dentro do conjunto destas tratativas o Acre legalmente se tornou parte constitutiva do Brasil em 17 de novembro de 1903, por meio da assinatura do Tratado de Petrópolis, solucionando a contenda com a Bolívia e findando as polêmicas de sua demarcação territorial com o Peru no acordo firmado no Rio de Janeiro de 1909, que fechava a questão entre Brasil e Peru. Assim, os brasileiros obtiveram legitimidade de exploração da borracha extraída da árvore da seringueira existente naquela região.

Todavia, em âmbito interno a "Questão do Acre" (como ficou registrada em livros e jornais) gerou polêmicas antes, durante e após sua resolução. Preliminarmente denotaram-se os aspectos de direito internacional (manifestos tanto em debates sobre soberania, quanto no caráter colonial com a proposta de arrendamento ao Bolivian Syndicate). O percurso foi pontuado por beligerância nos periódicos e os embates de tropas, indo desemborcaram na anexação territorial, com criação de novo ente federativo não previsto na Constituição de 1891. Resultando em pagamento de dois milhões de libras esterlinas, acrescido de "permuta" de terras entre o Abunã e Madeira pelo Acre, livre navegação boliviana em rios brasileiros para atingir o Atlântico e a construção da Ferrovia Madeira-Mamoré.

O Acre brasileiro de direito deu origem ao Território Federal homônimo, acarretando ampliação "territorial brasileira em mais de 200.00 km", ao mesmo tempo em que demonstrava descumprimento das "recomendações constitucionais" previstas no art. 88, Título V, das Disposições Gerais na Constituição de 1891 a respeito de não se "empenharem em guerra de conquista, direta ou indiretamente" a exemplo do que

\footnotetext{
${ }^{11}$ A este respeito ver FAUSTO, Boris. História Concisa do Brasil. São Paulo: Edusp, 2001. p. 85
} 
recordou Porto. ${ }^{12}$ Essa anexação do Acre ao Brasil, sob gestão direta da União, instituído pelo Decreto ${ }^{\circ} 1.181$ de 25 de fevereiro de 1904, conflitava aos interesses do governo do Amazonas conforme demonstrado em processo movido no Supremo Tribunal Federal que teve Rui Barbosa ${ }^{13}$ como um de seus patronos.

Tais controvérsias nas esferas políticas e jurídicas movimentaram debates a fim de sensibilizar a opinião pública por meio da imprensa antes, durante e após o desenrolar da "Questão do Acre”. A parte inicial da divergência, relativa ao Bolivian Syndicate, é o objeto de exame do presente artigo, tendo em conta como a escrita se relaciona com a história pública. Neste intuito foram fontes as publicações datadas entre os anos de 1899 a 1909, que circularam em jornais da capital federal, de Belém e Manaus, disponibilizados no acervo digital e físico da Fundação Biblioteca Nacional.

A opção por esse marco cronológico vincula-se as dissensões de domínio político e econômico sobre a região primeiro entre bolivianos e brasileiros, acrescido depois das contestações peruanas. Isto porque em 1899 a tentativa da Bolívia de instalação aduaneira em terras do Acre motivou o levante comandado por José Carvalho, seguido do movimento de "Estado Independente" liderado por Galvez, que foram sucedidos pelos conflitos militares entre brasileiros e bolivianos, solucionados por diplomacia bilateral. Entretanto, a "Questão do Acre" se prolongou até o Tratado do Rio de Janeiro em 1909.

Esses escritos jornalísticos publicados entre 1899 a 1909 foram analisados a luz de referências no trato das fontes hemerográficas constantes em Walnice Galvão, Marialva Barbosa, Tânia de Luca e José D’Assunção Barros. Ao passo que os dados históricos foram confrontados com as obras de Cunha ${ }^{14}$, Tocantins ${ }^{15}$; Calixto, Souza e Souza ${ }^{16}$;

\footnotetext{
12 PORTO, J. L. R. Os Territórios Federais e a sua evolução no Brasil. Revista Presença (Porto Velho), Porto Velho, n. 16, 2000.

${ }^{13}$ Documentação, peças redigidas e argumentação a esse respeito podem ser lidos em no livro de Rui Barbosa denominado O Direito do Amazonas ao Acre Setentrional. BARBOSA Rui. Obras completas de Rui Barbosa: o direito do Amazonas ao Acre setentrional. Vol. XXXVII, tomo V, 1910. Rio de Janeiro: Fundação Casa de Rui Barbosa, 1983.

${ }^{14}$ CUNHA, Euclides. À margem da História. São Paulo: Martins Fontes, 1999.

${ }^{15}$ TOCANTINS, Leandro. Formação Histórica do Acre. 4. ed. Brasília: Senado Federal, 2001.2 v. 548p.

${ }^{16}$ CALIXTO, Valdir de Oliveira; SOUZA, Josué Fernandes de; SOUZA, José Dourado de. Acre: uma história em construção. Rio Branco: Fundação Cultural,1985.
} 
Souza $^{17}$ e Carneiro ${ }^{18}$, sem perder de vista as ponderações a respeito história pública ${ }^{19}$, porquanto seu tripé de sustentação se faça presentes nas reflexões deste texto.

\section{Como a História Pública pode fazer repensar sobre a escrita da História do Acre?}

Para responder nossa indagação motriz, há de se recordar que é recorrente na historiografia ao lidar com a anexação do estado ao Brasil denominá-la de "Questão do Acre", apontando enquanto clássico acerca do tema a obra "Formação Histórica do Acre" 20 de Leandro Tocantins, assim como a análise de ocupação da área estar referenciada a partir de Euclides da Cunha (em "À Margem da História"21 e seus demais escritos sobre Amazônia, tanto quanto no seu trabalho da comissão de demarcação territorial na região do Alto Purus). ${ }^{22}$

Os dois autores pautam a construção das análises (históricas, geográficas e sociológicas da incorporação territorial e humana da planície amazônica) inaugurando, a nosso ver, o "acrianismo" em analogia ao "brasilianismo". Compreensão desligada de adjetivo pátrio, porquanto o termo independa das origens de autoria e desvincule a produção de ter sido redigida em terras acrianas, mas, seja correlato a produção sobre à região. $^{23}$

Entretanto, essa construção historiográfica até o início do XXI teria sido pontuada quanto a "Questão do Acre" em caráter uníssono pela versão dada por Leandro Tocantins. Narrativa com ênfase a participação de Luiz Galvez ao denunciar a propositura do Bolivian Syndicate e liderar o movimento de formação do Estado Independente do Acre, sustentado no governo do Amazonas.

\footnotetext{
${ }^{17}$ SOUZA, Carlos Alberto Alves de. História do Acre: novos temas, nova abordagem. Rio Branco: Carlos Alberto Alves de Souza, 2002.

${ }^{18}$ CARNEIRO, Eduardo de Araújo. 'A fundação do Acre': um estudo sobre comemorações cívicas e abusos da história. 2014. Tese (Doutorado em História Social) - Faculdade de Filosofia, Letras e Ciências Humanas, Universidade de São Paulo, São Paulo, 2014.

${ }^{19}$ FAGUNDES, Bruno Flávio Lontra; MELO, Ricardo Marques de; KOBELINSKI, Michel. História pública brasileira e internacional: seu desenvolvimento no tempo, possíveis consensos e dissensos. Revista do NUPEM, v. 11, p. 29-47, 2019.

${ }^{20}$ TOCANTINS, Leandro. Formação histórica do Acre. Brasília: Senado Federal, 2001, Vols. I e II

${ }^{21}$ CUNHA, Euclides da. À margem da história. São Paulo: Martins Fontes, 1999.

${ }^{22}$ GUIMARAES, Leandro Belinaso. Euclides da Cunha na Amazônia: descontinuidades históricas nos modos de ver e narrar a floresta. Hist. cienc. saúde-Manguinhos, Rio de Janeiro, v. 17, n. 3, p. 705-718, 2010. Disponível em: from <http://www.scielo.br/scielo.php?script=sci_arttext\&pid=S010459702010000300008\&lng=en\&nrm=iso >. Acesso em: 16 Jul. 2019. http://dx.doi.org/10.1590/S010459702010000300008 .

${ }^{23}$ ALBUQUERQUE, Nedy Bianca Medeiros de. A cavalo dado não se olham os dentes: o Bolivian Syndicate e a Questão do Acre na imprensa (1890-1909). Tese de Doutoramento em História Social pela FFLCH da USP: São Paulo, 2015, p. 54.
} 
A abordagem de Tocantins não tem sido questionada e seguiu sendo mantida a exemplo dos livros didáticos "Acre: uma história em construção" de Calixto, Souza e Souza $^{24}$, repetida na obra de Souza ${ }^{25}$ denominada "História do Acre: novos temas, nova abordagem". Tais leituras corroboraram a difusão de nativismo ufanistas, colocando o Acre como único estado que lutou para ser brasileiro e amplamente difundida nas propagandas governamentais acrianas (independente dos programas partidários e siglas políticas). Diante disto, qual seria a conexão da parte inicial da "Questão do Acre" ao diálogo entre a produção historiográfica nos usos da imprensa e história pública? Como a produção historiográfica se vincula ao supracitado dogma?

Em resposta a essas indagações, convém tomarmos como referencial Albuquerque $^{26}$ e Silva $^{27}$ para compreender a historiografia acriana, recordando que as narrativas históricas são influenciadas pelo lugar de produção ${ }^{28}$ de seus tempos presentes, por disputas políticas e (re)significações dos projetos de memória. Neste sentido, tanto a escrita, quanto os espaços de públicos acrianos destinados a produção historiográfica e a rememorar os fatos ligados ao processo de anexação territorial do Acre estão permeados do padrão dado em Tocantins.

Essa rota de nativismo ufanista se fortaleceu com museus, memoriais, bibliotecas e patrimônio histórico dentro do projeto político que governou o Acre entre 1999 a 2018. Assim, a História Pública com pouca difusão de seus referenciais na produção historiográfica acriana na primeira década do XXI, se impôs pelo caráter "cívico" governativo $^{29}$ e ganhou espaço na academia, motivando novos olhares.

\footnotetext{
${ }^{24}$ CALIXTO, Valdir de Oliveira; SOUZA, Josué Fernandes de; SOUZA, José Dourado de. Acre: uma história em construção. Rio Branco: Fundação Cultural,1985.

${ }^{25}$ SOUZA, Carlos Alberto Alves de. História do Acre: novos temas, nova abordagem. Rio Branco: Carlos Alberto Alves de Souza, 2002.

${ }^{26}$ ALBUQUERQUE, Nedy Bianca M. O Bolivian Syndicate nos livros didáticos de História do Acre. In: SOUZA, S. R. G.; SILVA, F. B. Diálogos sobre história, cultura e linguagens. 1. ed. Rio Branco: NEPAN, 2018. v. 1. p. 11-24.

${ }^{27}$ SILVA, Francisco Bento da. Insolitudes acres, hibridas e fronteiriças: as disputas pelas identidades. Revista Jamaxi, v. 1, p. 49-67, 2017.

${ }^{28}$ BARROS, José D’Assunção. A fonte histórica e seu lugar de produção. In: Caderno de Pesquisa do CDHIS/UFU. V.25, N.2, jul./dez. 2012. pp. 407-429. Disponível em: <http://www.seer.ufu.br/index.php/cdhis/article/"view/15209/11834> Acesso em: 04 mar. 2020.

${ }^{29}$ CARNEIRO, Eduardo de Araújo. 'A fundação do Acre': um estudo sobre comemorações cívicas e abusos da história. 2014. Tese (Doutorado em História Social) - Faculdade de Filosofia, Letras e Ciências Humanas, Universidade de São Paulo, São Paulo, 2014.
} 
Em função deste foco, coube a configuração de produções como Albuquerque ${ }^{30}$, Carneiro $^{31}$, Klein $^{32}$ e Silva ${ }^{33}$ na historiografia acriana a explorar não apenas fontes históricas acessíveis em locais de visitação (física ou digital) pública. Mas, buscar compreender como se encadeavam a tríade de sustentação da História Pública no contexto local. Analisando temas, espaços e relacionamentos (de produção, contato e diálogo) com a população dentro de metodologias e conceitos históricos.

No presente texto, nossa questão essencial se impulsiona pelo não dito, ou melhor, por inexistência de alusão à batalha de opinião pública e diplomática que estava entranhada na "Questão do Acre". Os silêncios sobre o Bolivian Syndicate, a predileção acerca da resolutiva "Revolução Acriana" de Plácido de Castro, em detrimento das manobras de Rio Branco e do governo amazonense controlando a compreensão do processo e da análise histórica nos instigaram. Daí o nosso obrigatório percurso de investigação pelas fontes hemerográficas e sua associação à História Pública.

Mas, para tanto é preciso recordar de Barbosa advertindo-nos "sobre o valor que os meios de comunicação atribuem ao passado" e que "significa também perceber como constroem suas narrativas com valor de futuro". ${ }^{34}$ Associando Barbosa com as advertências de Lapuente ao considerar todo e qualquer "periódico, independente de seu perfil" entrelaçado "em um jogo de interesses, ora convergentes, ora conflitantes." 35 Por isso, os escritos dos jornais de nossa baliza cronológica, as obras publicadas posteriormente e ora referenciadas tiveram seus relatos vinculados às crenças, vontades e proveitos de segmentos sociais não homogêneos - tais quais políticos, seringalistas, casas comerciais e bancárias.

Tendo essas ponderações em mente, compreende-se que a História Pública e a imprensa contribuem para dessacralizar o dogma acerca da ideia de "único estado

\footnotetext{
${ }^{30}$ ALBUQUERQUE, Nedy Bianca M. O Bolivian Syndicate nos livros didáticos de História do Acre. In: SOUZA, S. R. G.; SILVA, F. B. Diálogos sobre história, cultura e linguagens. 1. ed. Rio Branco: NEPAN, 2018. v. 1. p. 11-24.

${ }^{31}$ CARNEIRO, Eduardo de Araújo. 'A fundação do Acre': um estudo sobre comemorações cívicas e abusos da história. 2014. Tese (Doutorado em História Social) - Faculdade de Filosofia, Letras e Ciências Humanas, Universidade de São Paulo, São Paulo, 2014.

32 KLEIN, Daniel da Silva. A Amazônia no Ciclo da Borracha: populações e economia no Acre, Amazonas e Pará entre 1880 e 1920. In: Revista Estudos Amazônicos. v. 8, n. 02, 2012.

33 SILVA, Francisco Bento da. Insolitudes acres, hibridas e fronteiriças: as disputas pelas identidades. Revista Jamaxi, v. 1, p. 49-67, 2017.

${ }^{34}$ BARBOSA, Marialva. Imprensa e história pública. In: MAUAD, Ana Maria; ALMEIDA, Juniele R. de; SANTHIAGO, Ricardo (Org). História pública no Brasil: sentidos e itinerários. São Paulo: Letra e Voz, 2016. p. 126.

${ }^{35}$ LAPUENTE, Rafael Saraiva. O jornal impresso como fonte de pesquisa: delineamentos metodológicos. In: $10^{\circ}$ ENCONTRO DA REDE ALFREDO DE CARVALHO (ALCAR), 2015, Porto Alegre.
} 
sequioso de ser brasileiro". Isto porque, ao remetermos as fontes, entendemos tratar de anacronismo definir as terras acrianas entre 1890 a 1909 assemelhadas ao Acre de hoje, posto existirem as diferenças de território, população, ocupação, organizações sociais e políticas. Igualmente, não é possível constatar nos periódicos da época uma demonstração popular de vontade espontânea em vincular o Acre a União ou ao Amazonas.

E por fim, observamos que a construção da identidade do Acre é desde aqueles anos fruto de disputas, quer em associação ao homem civilizador euclidiano ou as múltiplas interferências do Estado Brasileiro na busca de disciplinar terras e viventes no/do Acre. Assim se constituindo "polissêmicas narrativas, situadas em tempos diversos, que atribuem ao Acre como espaço geográfico, unidade política e território socialmente vivido de distintas representações." 36

\section{Da construção do corpus documental: acesso, trato e lugares de produção.}

Ao considerarmos o "Acre polissêmico" somos encaminhados a pensarmos nos noticiários impressos como fontes ${ }^{37}$ apesar das advertências quanto aos seus usos. Entretanto, tais admoestações ${ }^{38}$ não são objeto de nossa análise e por isso não as exporemos aqui, ademais já assumimos a imprensa como manancial de pesquisa no constitutivo de História Pública. Entrementes, tais críticas e recomendações metodológicas são atendidas em nosso aporte referencial e reverberam no corpus documental, ${ }^{39}$ que reuniu materiais do Jornal do Brasil e $O$ Paiz publicados na capital brasileira; acrescido do Correio Paraense, A Província do Pará, O Pará: diário da tarde e Folha do Norte impressos em Belém; somados aos manauaras Diário Official do Amazonas, A Federação e Commercio do Amazonas.

A opção por trabalhar com os fluminenses Jornal do Brasil e $O$ Paiz adveio dos debates na capital federal acerca da "Questão do Acre" capitaneados entre as ideias de Rui Barbosa, do Barão do Rio Branco e seus respectivos entusiastas. O chanceler e o político tinham diferenças quanto as formas de atuação sobre a contenda fronteiriça, bem

\footnotetext{
${ }^{36}$ SILVA, Francisco Bento da. Insolitudes acres, hibridas e fronteiriças: as disputas pelas identidades. Revista Jamaxi, v. 1, p. 49-67, 2017.

${ }^{37}$ LUCA, Tania Regina de. Fontes impressas: História dos, nos e por meio dos periódicos. In: PINSKY, Carla Bassanezi (Org.) Fontes históricas. São Paulo: Contexto, 2005.

${ }^{38}$ CRUZ, Heloísa de Faria; PEIXOTO, Maria do Rosário da Cunha. Na oficina do historiador: Conversas sobre História e Imprensa. Projeto História: História e Imprensa, São Paulo, v. 35, ago./dez. 2007. Disponível em: <http://revistas.pucsp.br/index.php/revph/article/view/2221> Acesso em: 3 fev. 2020.

${ }^{39}$ A respeito do uso dos jornais como fontes ver: ALBUQUERQUE, N. B. M. História e Jornais: diálogos sobre a produção historiográfica. In: IV ENCONTRO REGIONAL NORTE DE HISTÓRIA DA MÍDIA, 2016, RIO BRANCO. ANAIS DO IV ENCONTRO REGIONAL NORTE DE HISTÓRIA DA MÍDIA, 2016. p. 1-13.
} 
como a administração do território anexado. Ao passo que a escolha pelas folhas belenenses e manauaras motivou-se por serem áreas de trânsito para o Acre, beneficiárias e financiadoras do comércio extrativista. Neste sentido, há de se compreender as fontes, seus respectivos lugares de produção e a representação da temática em suas páginas.

Para entendê-las, não podemos pensar os periódicos pesquisados a imagem e semelhança dos exemplares em circulação nos dias correntes, embora alguns tenham sido longevos a ponto de ainda estarem sendo editados, como é o caso do Jornal do Brasil e Diário Oficial do Amazonas. As publicações correntes estão disponíveis em formato impresso e digital, com atualizações virtuais no chamado tempo real. Os modos de contato entre leitores, redatores, anunciantes e dirigentes pode ser feito em âmbito físico ou virtual. Para além das vendagens, as visualizações e "curtidas" também se tornaram valores de importantes na contemporaneidade (algumas vezes prevalecendo sobre o conteúdo jornalístico e influenciando linhas editorais). A maneira de ler jornais foi alterada pela tecnologia, repercutindo a ponto de fazer com que endereços eletrônicos, redes sociais e espaços ocupado na internet se tornam mais relevante que um local físico. As notícias e anúncios podem ser construídos a partir de um telefone celular, tablet ou de um notebook, alcançando maior quantitativo de pessoas e distâncias geográficas, com menores gastos e recursos.

Ao observarmos a imprensa brasileira no fins do XIX e início do XX tocante as formas de interação, os volumes e tamanhos de seus projetos gráficos identificamos nas capitais estaduais a padronagem de seis a oito laudas, em apresentação no formato standard, preto e branco, letras pequeninas (excetuando-se os títulos), tendo primazia do texto em detrimento das imagens (a escassear em proporção ao afastamento do Rio de Janeiro), com páginas divididas em média por seis colunas inteiras, em que as notícias eram distribuídas de cima para baixo e quando necessário ocupando a próxima coluna. ${ }^{40}$

$\mathrm{Na}$ virada do XIX ao XX a periodicidade das folhas era variável, podendo ir do diário com edições matutina e vespertina (a exemplo do Jornal do Brasil), perpassando ao semanal ou quinzenal. Leitores e a redação podiam estabelecer diálogos por cartas (ocasionando que alguns periódicos inclusive tivesse uma sessão homônima em suas páginas), as vezes por telefone (prática comum em $O$ Paiz), sem excluir o contanto físico

\footnotetext{
40 Já na década de 1970 Walnice Nogueira Galvão alertava para as diferenças de configuração entre periódicos do XIX em comparação ao XX, além disso, enfatizava que a própria forma de contato com os jornais e de leitura eram distintas, sobre isso ler: GALVÃO, Walnice Nogueira. No calor da hora: a guerra de canudos nos jornais. 3.ed. São Paulo: Ática, 1994.
} 
que ocorria com a ida do leitor a sede do jornal a se fazer a anotação dos seus pedidos, reclamações ou contribuições de informações. ${ }^{41}$

A atualização das notícias advinha dos telegramas (que em várias publicações ganharam um espaço específico de vinculação) ou das agências. ${ }^{42}$ Contudo, não se obliterou nestas gazetas - fossem estatais ou privadas - a "percepção de que os textos que os historiadores tomam para fontes históricas também foram produzidos, em sua época, a partir de um lugar que precisa ser compreendido e decifrado pelo historiador." 43 Entendendo-as como fruto de um lugar de produção, tomamos esse conceito como preconiza Barros, ou seja, para além do espaço físico da elaboração impressa do jornal, compreendendo-o face às relações de poder que permeiam a sustentação da publicação. Logo, associando a imprensa escrita aos aspectos sociais e políticos concatenando donos de periódicos, financiadores, redatores, equipe gráfica e destinatários, a fim de descontruir a ideia de noticiários como "documento monumento". ${ }^{4}$

Desta feita, era necessário não perder de vista que o Jornal do Brasil criado por Rodolfo Dantas em 1891 inicialmente tinha caráter monarquista, contando nas duas primeiras décadas de funcionamento com a contribuição de textos escritos pelo Barão do Rio Branco. Entretanto, sem esquecer, que o Jornal do Brasil em 1893 ganha ascendência republicana após a constituição como Sociedade Anônima ${ }^{45}$, onde incluía-se Rui Barbosa dentre os sócios e a passagem da propriedade dos irmão Mendes Almeida em sua Almeida \& Cia. Ao passo que $O$ Paiz fundado em 1884 por João José dos Reis Júnior foi desde o início contrário à monarquia, tendo adotado postura política republicana mais conservadora a partir de sua aquisição pelo conselheiro Francisco de Paula Mayrink, que foi figura empresarial e política proeminente da Primeira República. Assim demonstrando as relações daquelas folhas com os bastidores políticos da capital federal durante o alvorecer republicano do Estado brasileiro.

Já nos jornais belenenses analisados não havia longevidade e configuração política uníssona, porquanto Correio Paraense tivesse circulado apenas entre 1892 a 1894, ao

${ }^{41}$ BARBOSA, Marialva. História Cultural da Imprensa: Brasil, 1800-1900. Rio de Janeiro: Mauad X, 2010.

42 MACIEL, Laura Antunes. Produzindo notícias e histórias: algumas questões em torno da relação telégrafo e imprensa - 1880 /1920. In: FENELON, Déa Ribeiro (Org.). Muitas memórias, outras histórias. São Paulo: Olho d'Água, 2005.

43 BARROS, José D'Assunção. A fonte histórica e seu lugar de produção. In: Caderno de Pesquisa do CDHIS/UFU. V.25, N.2, jul./dez. 2012. pp. 407-429. Disponível em: <http://www.seer.ufu.br/index.php/cdhis/article/"view/15209/11834> Acesso em: 04 mar. 2020.

${ }^{44}$ LE GOFF, Jacques. História e memória. Campinas: Editora UNICAMP, 1996. p. 538.

${ }^{45}$ BARBOSA, Marialva. História Cultural da Imprensa: Brasil, 1800-1900. Rio de Janeiro: Mauad X, 2010 . 
passo que A Província do Pará fundada por Antônio Lemos em 1876 circula atualmente em formato on-line. Exemplificando o contexto político podemos mencionar a Folha do Norte que foi caracterizada como uma gazeta simpatizante do Partido Republicano Democrático sob a liderança política de Lauro Sodré, sendo o projeto político do Partido Republicano Paraense defendido em O Pará e contando com apoio de A Província do Pará comandada por Antônio Lemos. Todavia, apesar de serem diários de caráter republicano, ambos repercutiram as polêmicas e confrontos políticos entre Lauro Sodré e Antônio Lemos travados na capital do Pará.

Em Manaus, o jornal A Federação criado em 1895 dizia em seu subtítulo dizia ser “órgão do partido republicano federal”. E os periódicos Commércio do Amazonas e o Diário Official teriam seus exemplares inaugurais datados de 1869 segundo João Batista Faria e Souza. ${ }^{46}$ A opção pelo diálogo com o Commércio do Amazonas decorre da caracterização tal qual se lê em Tocantins ${ }^{47}$ desse "como órgão oficial da República do Acre", vez que "um decreto do governo acriano o considerava seu porta-voz". Ao passo que o trato do Diario Official do Amazonas foi movido pelas escriturações fundiárias em função do Decreto ${ }^{\circ} 037$ de novembro de 1893, instituidor e regulatório da Repartição de Terras. ${ }^{48}$

E ainda que o período estudado corresponda aquilo que foi denominado por Sodré 49 como "jornais empresas" 50 tais características não se estendem a todos os noticiários pesquisados, porquanto alguns em Belém se adequassem melhor a ideia de "empreendimento individual", ou no caso de Manaus do financiamento estatal com o Diário Official do Amazonas, ao político-partidário a exemplo de A Federação (cujo subtítulo era "orgam do Partido Republicano Federal") ou $O$ Pará (que era "órgão político" ligado ao Partido Republicano Paraense).

\footnotetext{
${ }^{46}$ Há controvérsias quanto as datas de fundação tanto de Commércio do Amazonas e o Diario Official, pois na Imprensa Oficial do Estado do Amazonas se atribui a criação pela Lei n ${ }^{\circ}$ 01, de 31 de agosto de 1892, tendo circulado seu primeiro exemplar em 1893. Aqui se tomou por referência o levantamento de João Baptista Faria e Souza feito em 1908 que no centenário da imprensa no Brasil, que inventariou a imprensa do Amazonas de 1851 a 1908, divulgado na Revista do Instituto Histórico Geográfico Brasileiro. FARIA E SOUZA, João Baptista; SOUZA, Monteiro de; BAHIA, Alcides. A imprensa no Amazonas, 1851-1908. Manaus: Tipografia da Imprensa Oficial, 1908.

${ }^{47}$ TOCANTINS, Leandro. Formação Histórica do Acre. 4. ed. Brasília: Senado Federal, 2001. V.2, p.368. ${ }^{48}$ Que dentre outros aspectos (e principalmente antes da oficialização do Acre como brasileiro) pautava o reconhecimento de áreas em solo acriano a fim de assegurar a propriedade e eventualmente propiciar o financiamento para abertura de seringais.

${ }^{49}$ SODRÉ, Nelson Werneck. História da Imprensa no Brasil. Rio de Janeiro: Civilização Brasileira, 1966. ${ }^{50}$ BARBOSA, Marialva. História Cultural da Imprensa: Brasil, 1900-2000. Rio de Janeiro: Mauad X, 2007.
} 
Salvo A Província do Pará, cuja pesquisa foi desenvolvida na leitura e compilação in loco dos exemplares da coleção no acervo da Biblioteca Nacional, os acessos aos demais jornais ocorreram via Hemeroteca Digital da Fundação Biblioteca Nacional. Então, excetuando-se A Província do Pará, todas as gazetas referendaram a investigação pela forma de contato e lida destes materiais. Na Hemeroteca Digital os periódicos se localizavam via mecanismo de busca, em que se delimitava o lugar, período e nome do jornal, de modo a ser direcionado àquela coleção específica. Após o ingresso nas séries, se empregava o instrumento de investigação por palavras chave, a fim de localizar as ocorrências de Bolivian Syndicate, Acre, Luiz Galvez, Barão do Rio Branco e Plácido de Castro nos textos. Detectadas as incidências se fazia a primeira leitura dos materiais e preenchimento de fichas de pesquisa identificando o espaço destinado a expressão buscada, ou seja, se estavam disponibilizados em notícias, editoriais, anúncios, telegramas, bem como o(s) local(is) ocupado(s) na(s) página(s), verificava-se tratar de edição diária, dominical ou semanal (ou matutina e/ou vespertina), além de se observar a existência ou não de fotografia ou mapa ou ilustração com charge.

Após estas anotações, quando permitido pelas normas do acervo da Hemeroteca Digital se faziam cópia digitalizada dos jornais. Constituído o corpus documental, se realizavam novas leituras a fim de formulação de análise mais aprofundada de dados, que então passavam por cruzamento com os referenciais sobre "A Questão do Acre". Tais exames possibilitaram o refinamento da pesquisa nos resultantes das buscas quanto ao Bolivian Syndicate, Acre e Luiz Galvez, levando o agrupamento em categoria de abordagem sobre o Acre do período que nem sempre se coadunam ao conteúdo dos livros didáticos ${ }^{51}$ ou com as páginas de obras clássicas sobre o processo de anexação da região ao Brasil.

Embora o cerne deste artigo não seja o resultado destes procedimentos, mas as reflexões de como a História Pública colabora para a escrita tomando como ponto de estudo uma das etapas do processo de incorporação territorial do Acre, nos parece pertinente expor a seguir alguns dos principais resultantes da pesquisa, demonstrando o caráter diferente da interpretação sacralizada da História do Acre.

\section{Pensando os resultados da pesquisa}

\footnotetext{
${ }^{51}$ ALBUQUERQUE, Nedy Bianca M. O Bolivian Syndicate nos livros didáticos de História do Acre. In: SOUZA, S. R. G.; SILVA, F. B. Diálogos sobre história, cultura e linguagens. 1. ed. Rio Branco: NEPAN, 2018. v. 1. p. 11-24.
} 
A História do Acre tradicionalmente prima por dialogar somente com os últimos cento e trinta e oito anos, tomando como referência o ano de 1882 com o estabelecimento do Seringal Volta da Empresa por Neutel Maia e seus parceiros comerciais, no que hoje se conhece como a cidade de Rio Branco. ${ }^{52}$ A fixação de Maia na região da capital acriana é relatada como o início do processo de abrasileiramento do Acre, que levaria ao conflito entre os habitantes da região e os bolivianos.

Partindo desse mito fundador, se constituiu a apologia as personas heroicas dos seringalistas que viveram no Acre daquele período, retratados como brasileiros imbuídos de patriotismo ao combaterem as "ingerências" bolivianas sobre as terras acrianas, que afetavam a soberania da jovem república brasileira. A isso se segue a exaltação do combate liderado por Plácido de Castro, das tratativas diplomáticas de Rio Branco e da anexação do Acre como Território ao Brasil, finalizado com a ideia cotidiana de que seja brasileiro porque seus habitantes assim quiseram e lutaram...

Ao propormos o presente artigo não nos esquecemos que anterior a chegada de Neutel Maia já existiam populações indígenas habitando terras acrianas, contudo, nosso foco de atenção é a construção historiográfica do Acre a partir dos anos de 1880 e as contribuições da História Pública para tanto. Nesse sentido, defendemos que população originariamente acriana são os povos indígenas que lá viviam, portanto, a nosso ver, essas seriam de fato as pessoas que têm lutado para habitar o Acre. ${ }^{53}$ Contudo, ao estudarmos o processo de anexação do Acre ao Brasil, por seus silêncios, verificam-se as omissões a respeito das populações indígenas existentes naquele momento.

Voltando ao mito fundador de Neutel Maia e suas consequências, somos conduzidos a denso exercício de reflexão, de compreender aos seringalistas, seringueiros e migrantes que viveram no Acre entre os anos de 1880 a 1909 enquanto sujeitos sociais na construção identitária do Brasil da Primeira República. Para isso nos ocorre que o processo de (i)migração ${ }^{54}$ entre os anos de 1880 a 1902 de brasileiros ao Acre não pode ser analisado sem lembrarmos a abolição, proclamação da república, os grandes quantitativos dos ingressos de estrangeiros recrutados para trabalharem na agricultura (e posteriormente nas fábricas) do Sul e Sudeste do Brasil.

\footnotetext{
52 KLEIN, Daniel da Silva. A Amazônia no Ciclo da Borracha: populações e economia no Acre, Amazonas e Pará entre 1880 e 1920. In: Revista Estudos Amazônicos. v. 8, n. 02, 2012.

${ }^{53}$ A respeito das populações indígenas da Amazônia ler: COSTA, K. S. Apontamentos sobre a formação histórica da Amazônia: uma abordagem continental. Série Estudos e Ensaios (Faculdade Latino Americana de Ciências Sociais), v. 1, p. 90-114, 2009.

54 (I)migração grafada assim, pois, ao considerarmos que até 1903 o Acre não era oficialmente brasileiro, compreende-se tratar de processo de mobilidade entre países diferentes, logo, sendo imigração.
} 
Entre 1880 a 1909 o nordeste brasileiro sofreu grandes secas, vivenciou a alforria de escravos sem adoção de políticas de distribuição de terras ou inclusão destes trabalhadores no mercado de trabalho, fatores que ocasionaram a "disponibilidade" de pessoas para se deslocarem. Somando-se a isso também as campanhas de recrutamento e propaganda para o translado desses sujeitos. ${ }^{55}$ De onde verificamos que a movimentação foi significativa, apesar do desencontro de dados sobre um quantitativo exato. ${ }^{56}$ Porém, assim se torna possível enxergar o Acre como alternativa aos potenciais conflitos fundiários nordestinos. E por oportuno somos conduzidos a recordar que o desterro não seja sinônimo de patriotismo. Entrementes, nas leituras de obras sob influência de Tocantins acerca da temática em comento, observa-se degredo silente destas pessoas, impossibilitando o diálogo a respeito das causas de deslocamento ou reflexões aprofundadas quanto aos modos de vidas constituídos no Acre por esses sujeitos. E o caráter de deportação é repetido a tal ponto de fazê-lo ser classificado como Sibéria Tropical. $^{57}$

Ao nos debruçarmos sobre o corpus documental igualmente verificamos dissonância com o texto clássico de Tocantins, posto que as imisções bolivianas sobre o Acre não deveriam ser apreciadas como indevidas. A Bolívia antes de 17 de novembro de 1903 ao arrendar o Acre, ou tributar a produção de borracha, estava no exercício de sua soberania em terras então oficialmente tidas como suas. ${ }^{58}$

Por conseguinte, nos resta ainda dizer que, ao consultarmos as fontes hemerográficas, constatamos peculiaridades às personas heroicas na atuação do processo de incorporação territorial do Acre ao Brasil. Ou para melhor elucidar, tratam-se de interpretações alternativas, nas quais Galvez, Plácido de Castro e Barão do Rio Branco são lembrados, apresentados, depreciados ou esquecidos conforme a vontade, o período de análise e os interesses das elites locais.

\footnotetext{
${ }^{55}$ Embora Isabel Guillen tome como foco o diálogo sobre o período de migração dos nordestinos para a Amazônia durante a Segunda Guerra Mundial, faz uma breve introdução analisando o recrutamento de trabalhadores em momento antecedente, por isso, sugere-se ler: GUILLEN, Isabel C. M. A Batalha da Borracha. Propaganda política e migração nordestina para a Amazônia. Revista de Sociologia e Política, Curitiba, n.9, p. 95-102, 1997.

56 KLEIN, Daniel da S. Historiografia Amazônica: discutindo questões demográficas nos tempos da borracha. Revista Jamaxi, v. 3, p. 44-52, 2019. Disponível em: https://periodicos.ufac.br/index.php/jamaxi/article/view/2804. Acesso em: 20 jan. 2020.

${ }^{57}$ SILVA, Francisco Bento da. Acre, a Siberia tropical: prisões e desterros para as regiões do Acre em 1904 e 1910. 2. ed. Rio Branco: Nepan, 2017. v. 01. 340p.

${ }^{58}$ VERGARA, Moema de Rezende. Ciência, fronteiras e nação: comissões brasileiras na demarcação dos limites territoriais entre Brasil e Bolívia (1895-1901). Belém: Boletim do Museu Paraense Emílio Goeldi, Vol. 5, No 2, Maio/Agosto de 2010.
} 
Tendo em vista os apontamentos acima e dos dados apresentados em etapa final da presente segmentação do artigo, revisitar as fontes hemerográficas e pensar os dogmas da construção historiográfica sobre o Acre amplia a perspectiva de emprego dos meios de comunicação na elaboração de jogos narrativos. Porquanto "colocam-se em evidência não apenas aquilo que é lembrado, mas sobretudo o que se pode esquecer, produzindo um passado enquadrado e muitas vezes silenciado."59 Neste sentido, o presente texto contribui ao refinamento do debate histórico, ao fazer tornar premente a pergunta sobre os por quês dos esquecimentos documentais e para quais fins?

Diante da metodologia exposta no item anterior, as ocorrências das palavras de busca perfizeram mais de 200 anotações, constituindo grupamentos de notícias e classificados em que o Acre era empregado a referenciar odores e sabores, enquanto ponto de chegada ou partida de gentes e cargas, destino de anúncios fluviais e marítimos, região de litígios (na qualidade de terras demarcadas ou a demarcar). Além dos limites territoriais e fronteiriços, pelas leituras dos artigos ora comentados também se depreende as nuances da construção historiográfica, associando o Acre a personalidade heroicizadas, ironizadas ou olvidadas ao tempero dos interesses da elaboração identitária.

Nas páginas de O Paiz e do Jornal do Brasil o Acre como expressão de rastreamento aparece em boa parte das vezes a adjetivar olfato e paladar, tomando significância da terra distante em que brasileiros enfrentavam disputas fundiárias somente a partir de 1899, e ainda naquele mesmo ano configurando o Estado Independente. Contudo, empatia a manifestação de autonomia da área ocupada por brasileiros perdia espaço, face a maior ênfase ao líder do movimento, fazendo assim de Galvez ponto de debate, em lugar de sua causa e divergindo dos escritos de Tocantins. ${ }^{60}$

Isto porque o autor afirmou a respeito do Galvez pouco se saber dos antecedentes, mas, o ingresso dele ao Brasil seria datado de 1897, quando teria abandonado funções exercidas no corpo diplomático espanhol na Argentina. Ao investigarmos o Jornal do Brasil identificamos que Luiz Galvez entre 1893 a 1897 viveu no Rio de Janeiro, atuou como secretário do clube "Sport Frontão Brasileiro" ${ }^{61}$ e mais tarde teria se transformado em proprietário da associação desportiva convertida a empresa de recreação. ${ }^{62}$ Galvez

\footnotetext{
${ }^{59}$ BARBOSA, Marialva. Imprensa e história pública. In: MAUAD, Ana Maria; ALMEIDA, Juniele R. de; SANTHIAGO, Ricardo (Org). História pública no Brasil: sentidos e itinerários. São Paulo: Letra e Voz, 2016. p. 136.

${ }^{60}$ TOCANTINS, Leandro. Formação Histórica do Acre. 4. ed. Brasília: Senado Federal, 2001. Volume I, pp. 315 a 316 .

${ }^{61}$ JORNAL DO BRASIL, Rio de Janeiro, 14 jun. 1893, n 165, p. 2.

62 JORNAL DO BRASIL, Rio de Janeiro, 05 out. 1895, no 278, p. 4.
} 
ganhou novo destaque nas páginas da imprensa carioca em 1900 por ocasião do Estado Independente do Acre, quando se lia em $O$ Paiz a identificação do aventureiro da fronteira com o outrora introdutor e estimulador da jogatina na capital federal:

[...]Essa outra palavra - frontão - nos traz no bico da Penna o famoso nome de Luiz Galvez, ex-presidente da República do Acre.

- Que tem Judas com as almas dos pobres? perguntará o leitor, e nós respondemos que, segundo informações fidedignas, foi Galvez quem introduziu o jogo da pelota nesta infeliz capital, onde péga de galho, cria raízes, floresce e frutifica tudo quanto é máo.

Depois de incompatibilizado com todos os seus parceiros de jogatina, Galvez partiu para o Amazonas - a terra da promissão -, e de lá subiu até o Acre, onde pretendeu fundar um estado livre. ${ }^{63}$

Posteriormente a tais relatos, assevera Tocantins a partida de Galvez para o exílio europeu. Contudo, Tocantins que alegou ter pesquisado o Jornal do Brasil, não faz alusão ao incidente do habeas corpus de Galvez em julho de 1902. Essa omissão nos faz crer que apesar de Tocantins ter dito usar de biografias escritas por El Diario de Buenos Aires, Álvaro de Las Casas e Rodríguez Lira, primou por abordar o espanhol dentro da perspectiva de, construí-lo com traços remidores, resvalando no "quixotismo." ${ }^{64}$ A esse respeito é curioso constatar como a personalidade remissa de Galvez, criada por Tocantins, tem se repetido largamente nos textos de História do Acre.

Ainda nos periódicos cariocas observa-se que Plácido de Castro, a quem se atribui protagonismo na denominada inapropriadamente "Revolução Acriana" é persona quase silente, ou seja, pouquíssimo referenciada a exemplo de idêntico tratamento dispensado aos brasileiros que moravam no Acre. Logo, se não há espaço para Plácido, tampouco se mencionam os seus comandado da beligerância com as tropas bolivianas.

Mas, a omissão de Plácido de Castro não é tanto pelo conflito militar, quanto pela postura rebelde. Sua ocultação se relaciona a trajetória de rebelde federalista no sul do Brasil, quando se opôs a presidência do Marechal Floriano Peixoto. Em Plácido de Castro a não ordem confrontava o lema positivista inscrito na bandeira durante a Primeira República. Fato é que aqui se optou por não o enfocar com profusão, mas, compreendemos que o embate fronteiriço não motivou seu esquecimento pelos jornais.

A disputa lindeira era difundida na imprensa, inclusive via notas internacionais assinadas pelo próprio Barão do Rio Branco, tal qual se podia ler no The New York Times em 15 de junho de 1902:

\footnotetext{
${ }^{63}$ O PAIZ, Rio de Janeiro, 14 out. 1900, n 5851, p. 1.

${ }^{64}$ TOCANTINS, Leandro. Formação Histórica do Acre. 4. ed. Brasília: Senado Federal, 2001, V. I, p. 316.
} 


\section{WARNING TO INVESTORS}

Germans Are Urged to Let the Bolivian Syndicate Alone.

The Brazilian Minister in Berlin Points Out that Territory Concerned is Still in Dispute.

BERLIN, June 14. - The Brazilian Minister, Baron Rio Branco, has issued a warning to German investors against putting Money in the Bolivian Syndicate, because, he points out, the boundaries of the Province of Acre are uncertain. Brazil and Peru are claiming, and are still negotiating with Bolivia regarding the same.

Attempts last night to reach the gentlemen in this city Who are interested in the Bolivian Syndicate were not successful, most of them being out of town. Arthur S. Fairchild of Vermilye \& Co. was the only one of them who could be seen.

Mr. Fairchild Said, when the Berlin dispatch was read to him, that he had heard nothing about the statement made in it, and could give no information as to the correctness of the reportor or its bearing on the future of the Bolivian Syndicate.

As announced in a dispatch from Berlin June 4, F. W. Whitridge of New York left Berlin that Day for England after having arranged with the Deutscher Bank and other financial houses of Berlin to take shares in the Bolivian Syndicate of New York.

The object of getting German capital for this syndicate does not appear to have been because outside money was needed, but because August Belmont \& Co., Vermilye \& Co., Brown Brothers \& Co., Frederic P. Olcott, President of the Central Trust Company, and others composing the syndicate desired to broaden the international basis of the enterprise and thus obtain additional diplomatic support in the negotiations now pending between the syndicate and Brazil. It is through Brazilian territory that the Bolivian Syndicate must find na outlet for intercourse with the world. It is likely that the syndicate will also obtain some Belgian capital.

The Bolivian Syndicate has been authorized to administer fiscally, to police, and to govern 80.000 square miles of rubber forests in Bolivia, and the output of this country will have to be transported on Rivers which cross the Brazilian frontier. It will also pay na export duty to certain Brazilian States and chiefly to the State of Amazonas.

The apprehension of the Brazilian Government arising from the fact that Americans are obtaining fiscal rights in and police control over so vast a territory in Bolivia, a strip of which territory is claimed by Brazil, has created a difficulty which has made international partition and ownership desirable. American interests, however, Will predominate.

While Mr. Whitridge has been dealing with the financial interests of the syndicate Sir William Martin Conway, the explorer, who negotiated the syndicate's concession from Bolivia, has been in Berlin and has explained to the German Foreign Office the objects of the enterprise. It is understood that the Foreing Office will probably forward the aims of the Bolivian Syndicate, in which both American and German capital is now interested.

Brazil has obtained of Argentina the right to navigate certain Rivers which cross the boundaries of the two countries, and has long contended that Venezuela should concede similar rights with regard to the Orinoco River. It is consequently thought probable that Brazil Will yield to the request that Bolivian and Brazilian streams be opened to international navigation. ${ }^{65}$

Em tradução livre e resumida, lê-se alerta para que investidores germânicos abandonem o projeto, por se tratar de região em litígio, reivindicada por Brasil, Peru e Bolívia. Seguia-se narrativa sobre a busca destes financistas, tendo sido encontrado

${ }^{65}$ THE NEW YORK TIMES. June 15, 1902. Disponível em: https://newspaperarchive.com/ . Acesso em: 10 jan 2012. 
apenas o responsável pela Arthur S. Fairchild da Vermilye \& Co, que disse não poder se manifestar sobre o empreendimento. Outro acionista seria F. W. Whitridge de Nova York, que teria obtido junto a casas bancárias como Deutscher Bank capital para o Sindicato. Explicando-se o ingresso do capital alemão não por falta de dinheiro dos envolvidos (August Belmont \& Co., Vermilye \& Co., Brown Brothers \& Co., Frederic P. Olcott, Presidente da Central Trust Company e outros), mas, enquanto uma estratégia de alargamento das bases internacionais do empreendimento, pensando em suporte diplomático para atuar nas negociações do litígio fronteiriço. Preocupação permeada pela necessidade de circulação das mercadorias do Sindicato por terras brasileiras. $\mathrm{O}$ artigo prosseguia mencionando se tratar de faixa territorial de 80 mil milhas, em que o Sindicato teria poder fiscal e de polícia. Todavia, se enfatizava a necessidade de trânsito por terras e águas brasileiras, reconhecendo não obstante o pagamento de taxas de exportação a estados brasileiros às ameaças a soberania do Brasil.

A intervenção de Rio Branco acima, caracteriza aviso aos investidores que pretendiam participar do contrato de arrendamento das terras do Acre feita pelo governo boliviano a consórcio de acionistas reunidos no Bolivian Syndicate (em formato semelhante as chartered companies então existentes no continente africano). ${ }^{66}$ Curioso observar que a admoestação datava de julho de 1902, quando oficialmente ainda se desenvolviam as tratativas para o empreendimento, antecedendo inclusive a eclosão da rebelião liderada por Plácido Castro.

A advertência, embora tenha sido coletada em jornal norte americano, também foi obtida pela internet, via Newspaper Archive (que reúne acervos hemerográficos digitais de periódicos do continente americano desde o século XVII) não transcendendo a História Pública. Desta feita, o emprego de materiais coletados no The New York Times, assim como o corpus constituído e aqui analisado coadunam-se a observação feita por Fonseca ${ }^{67}$ quanto ao fato de que:

Hoje em dia, quando se fala em mídia, não se pensa mais somente naquelas que marcaram a história do século XX: imprensa escrita, rádio, televisão, cinema. As novas formas advindas das novas tecnologias de comunicação são cada vez mais associadas a elas, e as novas gerações têm com elas evidente familiaridade, sobretudo a internet e as modalidades de recursos

\footnotetext{
${ }^{66}$ A respeito do Bolivian Syndicate e sua caracterização em obras didáticas ler ALBUQUERQUE, Nedy Bianca M. O Bolivian Syndicate nos livros didáticos de História do Acre. In: SOUZA, Sérgio Roberto Gomes; SILVA, Francisco Bento da. Diálogos sobre história, cultura e linguagens. 1. ed. Rio Branco: NEPAN, 2018. v. 1. p. 11-24.

${ }^{67}$ LIMA E FONSECA, Thais Nívia de. Ensino de história, mídia e história pública. In: MAUAD, Ana Maria; ALMEIDA, Juniele R. de; SANTHIAGO, Ricardo (Org). História pública no Brasil: sentidos e itinerários. São Paulo: Letra e Voz, 2016. p. 185.
} 
ou ferramentas que ela permite acessar. [...] Disso deriva, portanto, o problema de divulgação do conhecimento histórico e dos usos possíveis desse conhecimento no ensino de História e seu papel na educação de uma forma geral. Com esse problema em foco, cabe a reflexão a partir do "conceito" de história pública, como um caminho para se pensar a função e os usos dessas mídias na divulgação da História como conhecimento academicamente produzido e como patrimônio coletivo.

Entretanto, ousa-se acrescer que não devemos pensá-la apenas como divulgadora, mas, igualmente associada a produção de conteúdo. Tal afirmação toma como exemplo o presente trabalho, resultante de corpus constituído em espaços públicos de memória hemerográficas, que se enquadram como locais de História Pública. Igualmente oportuno é considerar a notícia alertada no periódico estadunidense em função introdutória para referenciar Rio Branco nos diários pesquisados. Nesse sentido, por obviedade durante a baliza cronológica da investigação abundam menções a José Maria da Silva Paranhos Júnior, pois o Barão do Rio Branco assume a pasta das Relações Exteriores em 1902 e lá permanece até seu óbito em 1912.

O chanceler para além de ser teor de matérias, tinha sido um dos colaboradores dos primeiros tempos do Jornal do Brasil e continuou a redigir textos para o periódico, dentre outros noticiários, visando influenciar a opinião pública. Barbosa sobre a interação política das gazetas e o ministro Rio Branco aponta a vasta troca de cartas entre ele e José Carlos Rodrigues, recheadas de pedidos de favores junto à presidência da república, acrescidos de sugestões de artigos a serem publicados em que se faria o hoje denominado "marketing pessoal" do barão. A autora afirmou que as interferências eram tão intensas, a ponto de Rio Branco redigir com exatidão parte dos textos a serem divulgados. Incidentes que se intensificaram quando ele assumiu a pasta das relações exteriores, visto que:

[...] costumava pessoalmente redigir os artigos sobre questões polêmicas publicados ora no jornal de José Carlos Rodrigues, ora n'O Paiz, como corre, por exemplo, durante 'A Questão do Acre'.68

Não obstante tais meandros, Rio Branco é pontuado na historiografia acriana como o signatário do Tratado de Petrópolis (1903) e do acordo entre Brasil-Peru (1909), sem análises aprofundadas a sua atuação. ${ }^{69}$ Silêncios repetidos acerca do Bolivian

\footnotetext{
${ }^{68}$ BARBOSA, Marialva. História Cultural da Imprensa: Brasil, 1800-1900. Rio de Janeiro: Mauad X, 2010. p.186-187.

${ }^{69}$ ALBUQUERQUE FRANCO, N. B. M. A anexação do Acre ao brasil dentro do contexto de relações internacionais que conduziram a construção das fronteiras brasileiras (1580-1909). JAMAXI, v. 1, p. 124136,2017
} 
Syndicate. ${ }^{70}$ Por sua vez, o consórcio internacional de arrendamento do Acre tem sua menção inaugural nos periódicos amazônicos notadamente em Belém no A Província do Pará, em 03 de junho de 1899, no seu exemplar nº 7056:

\begin{abstract}
AINDA A QUESTÃO DO ACRE CASO SENSACIONAL

A serem exactas certas informações, de caracter reservado, que chegam ao nosso conhecimento, o papel do sr. José Paravicini, era reivindicação dos pretensos direitos do seu paiz, não se limitou aos actos ostensivos de pose, que chegaram à notícia do público.

Secretamente o ministro da Bolivia, procurou entrar em negociações com o governo de uma nação amiga, para obter a intervenção diplomatica, e talvez armada, d'essa potência em favor do seu país.

Por intermedio do respectivo consul se transmittiu ao dito governo a minuta de um accôrdo.

N'este se fazem importantes concessões, em materia de exportação de borracha, caso a pendência se resolva pela via diplomatica, e se estabelecem bases para a partilha de uma parte do territorio brazileiro, havendo guerra. Talvez possamos dar aos nossos leitores cópia d'este documento, que é, por todos os motivos interessantes, em uma das nossas primeiras edições. ${ }^{71}$
\end{abstract}

Nos jornais belenenses pesquisados, o quantitativo de incidências das expressões de busca Galvez e Bolivian Syndicate inexiste no Correio Paraense, posto o período de funcionamento daquela gazeta ter ido de 1892 a 1894. Contudo, considerando as pesquisas no Correio Paraense, A Província do Pará e Folha do Norte foram encontradas cinquenta e oito ocorrências do "Acre" configurando-o como o rio homônimo e terras adjacentes, variantes da conjugação do verbo acreditar, alusão a odores e sabores.

Ao passo que em Folha do Norte também não identificamos alusão ao espanhol ou ao consórcio empresarial, restringindo as referências a esse somente ao A Província do Pará. Entretanto, já na Folha do Norte se encontravam preocupações lindeiras em 1896 nas edições $n^{\circ} 274^{72}$ e $n^{\circ} 346^{73}$ com relatos sobre os trabalhos das comissões de demarcação, acrescido no mesmo ano de menções a formação de alfândegas no curso fluvial do Madre de Dios e Alto Acre. ${ }^{74}$ Enquanto em $O$ Pará que se vinculava ao Partido Republicano Paraense abordava de modo irônico a "Questão do Acre" e as ações lideradas por Galvez, incluindo a adoção de periódico manauara como diário oficial da república acriana, conforme se lia em 25 de agosto de 1899 na edição ${ }^{\circ}$ 519:

\footnotetext{
${ }^{70}$ A respeito do Bolivian Syndicate se enquadrar nos moldes das chatered companies ver: TOCANTINS, Leandro. Formação Histórica do Acre. 4.ed. Brasília: Senado Federal, Conselho Editorial, 2001, V.2., p. 51-52.:

${ }^{71}$ A PROVÍNCIA DO PARÁ, Belém, 3 jun. 1899, nº 7056, p. 1.

${ }^{72}$ FOLHA DO NORTE, Belém, 30 set.1896, nº 274, p. 2.

${ }^{73}$ FOLHA DO NORTE, Belém, 11 dez. 1896, no 346, p. 1.

${ }^{74}$ FOLHA DO NORTE, Belém, 15 nov.1896, no 320, p. 2.
} 


\begin{abstract}
A República do Acre
Tem nos causado hilariedade a notícia da fundação do novo paiz do Acre, que adoptou a forma republicana e, por causa das dúvidas, todas as leis brazileiras, inclusive as tarifas aduaneiras...

O presidente de tal república também não esqueceu a língua portugueza, e a nossa moeda.

O mais engraçado de tudo é considerar como orgam official o Commercio do Amazonas que se publica em Manáus.

Como é desopilativa a república do Acre!

Que pandego é o Galvez! Aquele sujeito esteve por aqui e sem dúvida ouviu falar da república de Cunany. Foi para o Acre, entendeu-se com uns seringueiros e eil-o presidente do Acre.

A capital e o seringal do sr. José.

O orgam official, por emquanto, um jornal de Manaús.

Tem espírito, o Galvez. ${ }^{75}$
\end{abstract}

O Pará foi dos jornais belenenses o que adotou postura mais crítica em relação ao espanhol e a sua empreitada, alegando dentre outras coisas que Galvez transpunha ao Acre suas jogatinas experimentadas em empreendimentos na capital federal. Tais alegações desconstroem o perfil heroico incutido nos textos de Tocantins e nas páginas de A Província do Pará. Sendo importante observar com estes periódicos, salvo os dois últimos, pouco interesse a contenda fronteiriça. Contudo, ao compararmos $O$ Pará e $A$ Província do Pará verificamos que embora esse também fosse pertencente a um membro do Partido Republicano Paraense, se diferencia por ter sido o denunciante do processo de arrendamento do Acre, demonstrando assim a falta de homogeneidade dentro daquela sigla partidária.

Outro destaque a ser feito sobre A Província do Pará é que, como dito anteriormente, foi o único dos periódicos pesquisados não digitalizado, entretanto, na coleção deste não há menção textual a Galvez e tampouco ao Bolivian Syndicate. Mas, foram encontradas duas ocorrências em que se falava do projeto do sindicato. Ademais, antes mesmo de julho de 1899 A Província do Pará já dedicava espaço para acompanhar o que chamava então de "questão brasileiro-boliviana" (sic). Fechando o exame dos jornais belenenses se verifica que o Acre (além de representar terra de chegadas e partidas para deslocamento de cargas e pessoas) era pautado na imprensa escrita da capital paraense por conta do comércio e tributação, em sobreposição a outros aspectos, ao sabor dos interesses da elite local.

Logo, se é visível o indicativo de falta de heterogeneidade nas gazetas belenenses, homogeneidade também carecia aos diários manauaras quando o assunto era o Acre. Porém, é importante ressaltar como primeira grande distinção entre Belém e Manaus o

\footnotetext{
${ }^{75}$ O PARÁ, Belém, 25 ago. 1899, nº 519, p.1.
} 
fato de que eram cidades com tempos de existências e relevâncias socioeconômica distintas. Sendo a primeira o centro de referência em número populacional e de comércio na região amazônica, ao passo que a última estava em pleno processo de consolidação. ${ }^{76}$

Dentro desse contexto, ao pesquisarmos nos periódicos da capital amazonense igualmente se encontra a alusão ao Acre do verbo, do gosto e do cheiro, também das chegadas e partidas e dos avisos marítimos. Contudo, em Manaus estava sediado e publicado o Commércio do Amazonas em que Galvez teria atuado como jornalista por um curto espaço de tempo, afora ter sido o jornal apontado como diário oficial de uma república criada no Acre. A asseveração por si só já era inusitada, pois, ao declarar-se independente o Acre não tinha imprensa oficial no seu território e a constituía no Amazonas que a época integrava a federação de país distinto ao recém-criado.

Todavia, a condição de oficialização dos negócios do Acre na imprensa manauara era anterior ao levante liderado por Galvez, visto que os seringais acrianos eram aberto com auxílio financeiro das casas comerciais de Manaus e tinham seu "reconhecimento" de propriedade em conformidade com o Regulamento do Registro de Terras do estado do Amazonas (Decreto No 37 de 08 de novembro de 1893). Há de se destacar que o art. 29 do referido decreto instituía a criação de subprefeituras as margens do Rio Acre, segundo Albuquerque:

Para além de mero ato normativo, a criação de subprefeituras na região do rio Acre era a configuração de estrutura administrativa, política, fiscal e jurídica em terras oficialmente alheias ao Brasil, mas que na prática eram submetidas aos representantes do Estado Brasileiro.

Em bom português, naquele período se dizia em tratativas diplomáticas que o Acre era boliviano, porém suas terras eram ocupadas por nativos brasileiros e burocracia amazonense. Desta feita, por meios tortuosos se efetiva o brocado jurídico do uti possidetis, ita possideatis, ou seja, "como possuíeis, seguireis possuindo", nada mais sendo que a representação do Principio de Direito Internacional pelo qual se prioriza a posição de quem detem posse de terras contestadas.

Então, entre palavras de deferência expandiam-se as áreas de seringais brasileiros na região em litígio e concomitantemente alimentavam-se publicações no Diario Official do Amazonas que versavam sobre terras acrianas, conforme se via em vários exemplares no decorrer do ano de $1894 .^{77}$

Corroborando a isso, se constatou no Diario Official do Amazonas a presença de Galvez como solicitante de reconhecimento da obtenção de terras no município de Tefé. De tal modo que, ao pesquisar o nome do espanhol naquele periódico foram marcadas 27

\footnotetext{
${ }^{76}$ DAOU, Ana Maria. A Belle Époque Amazônica. (Descobrindo o Brasil).3. ed. Rio de Janeiro: Jorge Zahar Editor,2000. pp.7-8.

77 ALBUQUERQUE, Nedy Bianca Medeiros de. A cavalo dado não se olham os dentes: o Bolivian Syndicate e a Questão do Acre na imprensa (1890-1909). Tese de Doutorado em História Social pela FFLCH da USP, São Paulo: 2015. P. 149.
} 
ocorrências vinculadas a esta questão fundiária para "empresa extrativista" e 01 única menção a sua participação no projeto do Acre Independente conforme constava no dia 25 de agosto de $1899 .{ }^{78}$ Tais circunstâncias expuseram a tentativa de Galvez se enquadrar no perfil da elite amazonense, entretanto, além disto o próprio Tocantins apresenta a relação entre o espanhol e o governo de Ramalho Júnior. ${ }^{79}$ E não obstante o Diário Official do Amazonas ter a recorrente presença de Galvez, não encontramos a expressão Bolivian Syndicate em meio as 1554 incidências do Acre naquele periódico.

Passando a análise dos jornais privados manauaras e tomando como objetos de investigação Commércio do Amazonas foram identificadas 305 ocorrências do Acre, 12 referências a Questão do Acre, 05 menções a Galvez, e em nenhuma ocasião o termo Bolivian Syndicate. Ao passo que em A Federação foram 153 vezes encontradas a palavra Acre, mas somente 11 alusões à Questão do Acre e 05 referenciaram Galvez. Tal qual o Commercio do Amazonas, em A Federação não encontramos Bolivian Syndicate.

Comparando as maneiras de tratamento destinadas a Galvez em ambos os periódicos, se torna evidente a forma respeitosa mantida pelo Commercio do Amazonas a exceção, da publicação da carta de José de Carvalho que relatava o período do espanhol como gestor do Acre. Enquanto A Federação era ácida ao escrever sobre Galvez e seu governo. Ponto pacífico entre os dois diários era a interpretação do Acre como uma gleba do Amazonas, e por isso mesmo, despertando a atenção de sua imprensa.

\section{Considerações Finais}

Ao propormos o presente texto acerca da trajetória do Acre, enfocando a sua anexação ao Brasil a partir de jornais que circularam no Rio de Janeiro, Belém e Manaus entre 1890 a 1909, se pretendeu pensar as interações entre História Pública e Imprensa na elaboração da historiografia. Neste intuito foi feita introdução ao artigo contextualizando o processo de incorporação das terras acrianas ao Brasil, reportando-se de modo breve a dança das linhas de fronteiras pelos diferentes tratados dos períodos colonial e imperial, cujos ônus foram herdados pela república brasileira.

Em seguida se apresentou nossa questão motriz, ou seja, os contributos da História Pública ao repensar a escrita e compreensão histórica da anexação do Acre ao Brasil, a associando ao dogma de patriotismo enquanto produto de obstinada vontade dos habitantes das terras acrianas (que teriam lutado para fazê-las brasileiras). E após

\footnotetext{
${ }^{78}$ DIARIO OFFICIAL DO AMAZONAS, Manaus, 25 ago. 1899, nº 1659.

79 TOCANTINS, Leandro. Formação Histórica do Acre. 4. ed. Brasília: Senado Federal, 2001. V.2, p. 376.
} 
reflexões sobre o Acre polissêmico, com fito de desconstrução desse axioma, se passou a elaboração do corpus documental aqui analisado, pontuando que as formas de contato com as fontes primaram pela escolha de acervos hemerográficos de acessos disponibilizados na internet em locais de visitação não restrita. Tais opções, bem como a metodologia de trabalho foram permeadas pela dessacralização das fontes hemerográficas, bem como o confronto dos dados coletados. Neste sentido, o diálogo com os periódicos considerou ao interpretar as informações os lugares de produção a luz do conceito estabelecido por Barros, que nortearam os enfoques e silenciamentos das palavras-chaves no nosso instrumento de pesquisa.

Em conformidade com tais procedimentos, ao pensarmos os resultados da pesquisa afirmamos que foram prospectados mais de 200 escritos jornalísticos (que iam de notícias, textos telegrafados e anúncios) referentes ao Acre, Galvez e Bolivian Syndicate. Ao cotejá-los verificamos a tendência da historiografia acriana em seguir a linha traçada por Tocantins, sem problematizar sua versão, tampouco questionar a narrativa heroicizada de personas. Ao mesmo tempo, em que percebemos a peculiaridade nas fontes hemerográficas dos relatos, permeados pelos interesses dos grupamentos de poderes locais. E concluímos que a História Pública permite o lançamento de outros olhares sobre temas consagrados, colaborando com a escrita historiográfica a partir de novas reflexões.

Data de submissão: 06/05/2020

Data de aceite: 07/08/2020 
Referências Bibliográficas

ALBUQUERQUE FRANCO, N. B. M. A anexação do Acre ao brasil dentro do contexto de relações internacionais que conduziram a construção das fronteiras brasileiras (15801909). JAMAXI, v. 1, p. 124-136, 2017.

ALBUQUERQUE, N. B. M. História e Jornais: diálogos sobre a produção historiográfica. In: IV ENCONTRO REGIONAL NORTE DE HISTÓRIA DA MÍDIA, 2016, RIO BRANCO. ANAIS DO IV ENCONTRO REGIONAL NORTE DE HISTÓRIA DA MÍDIA, 2016. p. 1-13.

ALBUQUERQUE, Nedy Bianca M. O Bolivian Syndicate nos livros didáticos de História do Acre. In: SOUZA, S. R. G.; SILVA, F. B. Diálogos sobre história, cultura e linguagens. 1. ed. Rio Branco: NEPAN, 2018. v. 1. p. 11-24.

ALBUQUERQUE, Nedy Bianca Medeiros de. A cavalo dado não se olham os dentes: o Bolivian Syndicate e a Questão do Acre na imprensa (1890-1909). Tese de Doutoramento em História Social pela FFLCH da USP: São Paulo, 2015.

ALMEIDA, Juliele Rabêlo de; OLIVEIRA ROVAI, Marta Gouveia de (Org.). Introdução à História Pública. São Paulo: Letra e Voz, 2011.

BARBOSA Rui. Obras completas de Rui Barbosa: o direito do Amazonas ao Acre setentrional. Vol. XXXVII, tomo V, 1910. Rio de Janeiro: Fundação Casa de Rui Barbosa, 1983.

BARBOSA, Marialva. História Cultural da Imprensa: Brasil, 1900-2000. Rio de Janeiro: Mauad X, 2010.

BARBOSA, Marialva. Imprensa e história pública. In: MAUAD, Ana Maria; ALMEIDA, Juniele R. de; SANTHIAGO, Ricardo (Org). História pública no Brasil: sentidos e itinerários. São Paulo: Letra e Voz, 2016. p. 126.

BARROS, José D'Assunção. A fonte histórica e seu lugar de produção. In: Caderno de Pesquisa do CDHIS/UFU. v.25, n.2, jul./dez. 2012. p. 407-429. Disponível em: <http://www.seer.ufu.br/index.php/cdhis/article/view/15209/11834> Acesso em: 04 mar. 2020.

CALIXTO, Valdir de Oliveira; SOUZA, Josué Fernandes de; SOUZA, José Dourado de. Acre: uma história em construção. Rio Branco: Fundação Cultural,1985.

CARNEIRO, Eduardo de Araújo. 'A fundação do Acre': um estudo sobre comemorações cívicas e abusos da história. 2014. Tese (Doutorado em História Social) - Faculdade de Filosofia, Letras e Ciências Humanas, Universidade de São Paulo, São Paulo, 2014.

COSTA, K. S. Apontamentos sobre a formação histórica da Amazônia: uma abordagem continental. Série Estudos e Ensaios (Faculdade Latino Americana de Ciências Sociais), v. 1, p. 90-114, 2009.

CRUZ, Heloísa de Faria; PEIXOTO, Maria do Rosário da Cunha. Na oficina do historiador: Conversas sobre História e Imprensa. Projeto História: História e Imprensa, 
São Paulo, v. 35, ago./dez. 2007. Disponível em: <http://revistas.pucsp.br/index.php/revph/article/view/2221> Acesso em: 3 fev. 2020.

CUNHA, Euclides da. À margem da história. São Paulo: Martins Fontes, 1999.

DAOU, Ana Maria. A Belle Époque Amazônica. (Descobrindo o Brasil).3. ed. Rio de Janeiro: Jorge Zahar Editor,2000. pp.7-8.

FAGUNDES, Bruno Flávio Lontra; MELO, Ricardo Marques de; KOBELINSKI, Michel. História pública brasileira e internacional: seu desenvolvimento no tempo, possíveis consensos e dissensos. Revista do NUPEM, v. 11, p. 29-47, 2019.

FARIA E SOUZA, João Baptista; SOUZA, Monteiro de; BAHIA, Alcides. A imprensa no Amazonas, 1851-1908. Manaus: Tipografia da Imprensa Oficial, 1908.

FAUSTO, Boris. História Concisa do Brasil. São Paulo: Edusp, 2001. p. 85

GALVÃO, Walnice N. No calor da hora: a guerra de canudos nos jornais. 3.ed. São Paulo: Ática, 1994.

GUILLEN, Isabel C. M. A Batalha da Borracha. Propaganda política e migração nordestina para a Amazônia. Revista de Sociologia e Política, Curitiba, n.9, p. 95-102, 1997.

GUIMARAES, Leandro Belinaso. Euclides da Cunha na Amazônia: descontinuidades históricas nos modos de ver e narrar a floresta. Hist. cienc. saúde-Manguinhos, Rio de Janeiro, v. 17, n. 3, p. 705-718, 2010. Disponível em: from $<$ http://www.scielo.br/scielo.php?script=sci_arttext\&pid=S0104-

59702010000300008\&lng=en\&nrm=iso>. Acesso em: $16 \quad$ Jul. 2019. http://dx.doi.org/10.1590/S0104-59702010000300008.

KLEIN, Daniel da S. Historiografia Amazônica: discutindo questões demográficas nos tempos da borracha. Revista Jamaxi, v. 3, p. 44-52, 2019. Disponível em: https://periodicos.ufac.br/index.php/jamaxi/article/view/2804. Acesso em: 20 jan. 2020.

KLEIN, Daniel da Silva. A Amazônia no Ciclo da Borracha: populações e economia no Acre, Amazonas e Pará entre 1880 e 1920. In: Revista Estudos Amazônicos. v. 8, n. 02, 2012.

LAPUENTE, Rafael Saraiva. O jornal impresso como fonte de pesquisa: delineamentos metodológicos. In: $1^{\circ}$ ENCONTRO DA REDE ALFREDO DE CARVALHO (ALCAR), 2015, Porto Alegre.

LE GOFF, Jacques. História e memória. Campinas: Editora UNICAMP, 1996. p. 538.

LIMA E FONSECA, Thais Nívia de. Ensino de história, mídia e história pública. In: MAUAD, Ana Maria; ALMEIDA, Juniele R. de; SANTHIAGO, Ricardo (Org). História pública no Brasil: sentidos e itinerários. São Paulo: Letra e Voz, 2016. p. 185.

LUCA, Tania Regina de. Fontes Impressas: História dos, nos e por meio dos periódicos. In: PINSKY, Carla Bassanezi (org.). Fontes históricas. São Paulo: Contexto, 2005. 
MACIEL, Laura Antunes. Produzindo notícias e histórias: algumas questões em torno da relação telégrafo e imprensa - 1880 /1920. In: FENELON, Déa Ribeiro (Org.). Muitas memórias, outras histórias. São Paulo: Olho d’Água, 2005.

PORTO, J. L. R. Os Territórios Federais e a sua evolução no Brasil. Revista Presença (Porto Velho), Porto Velho, n. 16, 2000.

SILVA, Francisco Bento da. Acre, a Siberia tropical: prisões e desterros para as regiões do Acre em 1904 e 1910. 2. ed. Rio Branco: Nepan, 2017. v. 01. 340p.

SILVA, Francisco Bento da. Insolitudes acres, hibridas e fronteiriças: as disputas pelas identidades. Revista Jamaxi, v. 1, p. 49-67, 2017.

SODRÉ, Nelson Werneck. História da Imprensa no Brasil. Rio de Janeiro: Civilização Brasileira, 1966.

SOUZA, Carlos Alberto Alves de. História do Acre: novos temas, nova abordagem. Rio Branco: Carlos Alberto Alves de Souza, 2002.

TOCANTINS, Leandro. Formação histórica do Acre. Brasília: Senado Federal, 2001, Vols. I e II

VERGARA, Moema de Rezende. Ciência, fronteiras e nação: comissões brasileiras na demarcação dos limites territoriais entre Brasil e Bolívia (1895-1901). Belém: Boletim do Museu Paraense Emílio Goeldi, Vol. 5, No 2, Maio/Agosto de 2010. 